\title{
TQM techniques as an innovative approach in sport organisations management: toward a conceptual framework
}

\section{Gadaf Rexhepi}

Faculty of Business and Economics, South East European University, Tetovo, Macedonia

Email: g.rexhepi@seeu.edu.mk

\section{Veland Ramadani*}

Faculty of Business and Economics, South East European University, Tetovo, Macedonia and Faculty of Economics, AAB College, Kosovo Email: v.ramadani@seeu.edu.mk *Corresponding author

\section{Vanessa Ratten}

La Trobe Business School,

La Trobe University,

Melbourne, Australia

Email: v.ratten@latrobe.edu.au

\begin{abstract}
One of the most important aspects that sport organisations need to pay attention when it comes to being competitive is the use of total quality management (TQM) techniques. The aim of this paper is to develop a conceptual framework of the use and influence of TQM techniques in the sports organisations' performance by providing the relationship between these techniques and overall performance. Our conceptual framework is based on the influence of these techniques: quality circles, benchmarking, continuous improvement (kaizen), empowerment and outsourcing. These techniques contribute to increase the overall quality, increase innovations, increase the employees' involvement and loyalty and increase the financial stability of sport organisations.
\end{abstract}

Keywords: total quality management; TQM; TQM techniques; sport organisation; quality programs; performance.

Reference to this paper should be made as follows: Rexhepi, G., Ramadani, V. and Ratten, V. (2018) 'TQM techniques as an innovative approach in sport organisations management: toward a conceptual framework', Int. J. Business and Globalisation, Vol. 20, No. 1, pp.18-30. 
Biographical notes: Gadaf Rexhepi is an Associate Professor at South-East European University of Tetovo. He is the author of more than 40 research papers in different peer and refereed journals around the world. He is also the author and co-author of several text books and monographs, such as Strategic Management, Game Theory, Total Quality Management, Introduction to Business, Direct Marketing and Small Business, The Role of Institutions in Economic Development, etc. He works as a Consultant in Business Development Centre at South East European University and is active as an expert in some committees in the Ministry of Economy in Macedonia.

Veland Ramadani is an Associate Professor at South-East European University, Republic of Macedonia, where he teaches both undergraduate and post-graduate courses in entrepreneurship and small business management. He is also a Lecturer of Entrepreneurship at AAB College, Republic of Kosovo. His research interests include entrepreneurship, small business management and venture capital investments. He authored or co-authored more than 70 research articles and 15 books. Among his recent books is Entrepreneurship and Management in an Islamic Context, published by Springer. $\mathrm{He}$ is an Associate Editor of Int. J. Entrepreneurship and Small Business and serves as a member of editorial and reviewer board of several international journals.

Vanessa Ratten is an Associate Professor (Entrepreneurship and Innovation) at La Trobe Business School, La Trobe University. She is the Discipline Coordinator of Entrepreneurship and Innovation at La Trobe Business School. She teaches undergraduate, post-graduate and executive education courses on entrepreneurship, innovation, sport innovation, management and marketing for sustainable value creation and entrepreneurial business planning. Her main research areas include entrepreneurship (especially sport entrepreneurship, developing country entrepreneurship and international entrepreneurship) and innovation (focusing on technological innovation, cloud computing, mobile commerce). She has published on a wide range of subjects including European entrepreneurship, Asian entrepreneurship and tourism marketing.

\section{Introduction}

Most of US organisations rank the quality of products and services in the first and second place, as a condition for the success of their organisations (Schermerhorn, 1993). For every organisation, including sport organisation, initially it is very important to define what quality for them represents. This, as Crosby (1979) notes, is important because organisation would not be able to know what they are doing for its improvement and how to manage it. According to ISO 9000: 2000, quality is defined as "the degree that certain essential features meet the requirements" [Besterfield et al., (2003), p.8]. In defining of 'quality', managers need to know and understand what the mission of their organisation is, what the goals of every department are or what the requirements of customers are?

One of the main problems relating quality is that organisations usually tend to have quality in one sector, but not in the whole organisation. Some employees in one department perform in a very quality way, some others remain behind, or, organisations tend to perform with quality in one period and show deficiency in another one. This 
problem occurs in sport organisation as well. Managers of sport organisations need to implement quality programs for every department and everyone need to be part of the quality improvement in the entire organisation.

When we talk about quality programs we include many formal quality management initiatives such as: total quality management (TQM), quality certification, quality awards (QA) and all TQM techniques whose goal is to improve the overall quality of an organisation (Lobo and Jones, 2003). A number of studies and researches have concluded that organisations that use quality programs demonstrate better teamwork and make better decisions in comparison with those which do not use quality programs (Beheshti and Lollar, 2003; Karastathis et al., 2014).

The aim of this paper is to review of the relevant literature on TQM and its importance for sport organisations and based on this to provide a conceptual framework for the managers of sport organisations in order to identify and select the appropriate TQM technique or combination of them toward the improvement of the overall quality in their organisations.

The paper is structured as follows. In the beginning is provided an explanation of the TQM concept and its importance for the sport organisations. Quality programs and organisational benefits are discussed in Section 2. Section 3 elaborates the main TQM techniques and the conceptual model. The paper ends with the conclusion section.

\section{TQM in sport organisations}

Sport management disciplines have grown significantly in the past decade (Dana and Ramadani, 2015; Ratten, 2015, 2011a, 2011b). The best way for sport organisations to use quality programs and improve its efficiency is through the TQM and its techniques. TQM is the best technique that can use quality as best competitive advantage for sport organisations. According to Nová (2013) "the TQM concept in sport stresses the consumer - focused management system which stems from full involvement of the entire organisational workforce in improving quality" (p.2). But this we call TQM in its first form started from 1920 when Frederick Taylor made efforts to improve the quality in organisation (Smith., 1999). The evolution that followed brought it to what we know today as TQM. TQM was firstly developed in 1940 by Deming who did not achieve to persuade the American managers to use this concept. The concept then, for the first time was used in Japan, where it showed great results. TQM for the first time in USA was used during the $80 \mathrm{~s}$ of the last century and was known as total quality control (Park Dahlgaard, 1999).

TQM means everybody's involvement in executing its activities in the most qualitative way. Everyone in the sport organisations needs to improve the way how he is doing things; he needs to improve his overall performance. Everybody should try to improve the quality on how he executes his work. This is a very important to be understand by sport organisations. The responsibility of everybody involvement lays at senior managers (Hegazy, 2012; Sarkar, 1991). TQM sees organisation as system and if someone has made a mistake, this will influence everyone in the organisation. TQM is not a goal; it is a process, as Walter Deming pointed out, 'you need to do it forever' (Cohen, 2012). TQM stimulates proactive thinking. 


\section{Quality programs and organisational benefits}

Lobo and Jones (2003) have concluded that the implementation of quality programs, such as business improvement, TQM, and QA programs are more likely amongst high growth-oriented organisation than in those with moderate or low growth. They pointed out that implementation of quality programs by organisations, in majority of cases, brings more benefits than costs, respectively the benefits overcome the costs made for their implementation. Implementation of quality programs in almost all cases showed a positive result and they were related with the organisational survival and growth (Kalia and Elmazi, 2012). Implementing quality programs usually shows improvement in costumers satisfaction and employee satisfaction, higher improvement in service quality, increased market share, improved efficiency and productivity, and better employee relations (Beheshti and Lollar, 2003; Prabhjot and Kumar, 2014). Some benefits from these programs are shown in Table 1 and Table 2.

Table 1 The impact of quality management on performance

\begin{tabular}{lcc}
\hline Mean rating (1-5) & & \\
\hline Performance & Using quality programs & Not using quality programs \\
\hline Improved product quality & 4.00 & 4.57 \\
Increased efficiency & 4.88 & 4.57 \\
Improved customer service & 4.63 & 4.48 \\
Resulted in cost reduction & 4.00 & 2.90 \\
Improved decision making & 3.63 & 3.57 \\
Resulted in less defects & 3.05 & 2.25 \\
Encouraged teamwork & 3.35 & 2.88 \\
Increased productivity & 3.72 & 3.56 \\
Composite index & 3.91 & 3.60 \\
\hline
\end{tabular}

Source: Adapted from Beheshti and Lollar (2003)

Table 2 The importance of quality management in organisations

\begin{tabular}{lcc}
\hline Mean rating (1-5) & & \\
\hline Performance & Using quality programs & Not using quality programs \\
\hline Quality is critical to profitability & 4.52 & 3.89 \\
Quality increased market share & 4.45 & 4.22 \\
Employee training and development & 4.65 & 4.00 \\
Charge premium price & 3.86 & 3.56 \\
Quality is a competitive advantage & 3.69 & 3.11 \\
Value-added & 3.89 & 3.00 \\
Corporate strategy & 3.50 & 3.30 \\
Composite index & 4.08 & 3.58 \\
\hline
\end{tabular}

Source: Adapted from Beheshti and Lollar (2003) 
As it can be seen from Tables 1 and 2, organisations that use quality programs, in almost all the cases, show better performance in comparison with those which do not use quality program (see Wang, 2015). These differences are obviously emphasised in reducing cost, making fewer defects and encouraging teamwork.

Smith and Stewart (1999) claim that "products and services that emanate from the commercial sector in general and from governmental work are provided in the highest levels of quality. The adoption of quality management practices by the majority of the community demonstrates even more that sport services are often below base level" (p.62). If a sport organisation does not implement quality programs to improve its overall quality, then there is a real possibility this organisation to increase its internal and external costs. The cost of quality do not distinguish from other costs, it can be measured, programmed and analysed. According to Joseph Juran [as cited in Davis et al., (1999), p.144], quality costs are divided into three categories: prevention costs, appraisal costs and failure costs. Implementing a quality programs, such is TQM and its techniques, will increase the prevention costs, but will decrease the other types of costs.

Figure 1 Effects of quality program in costs (see online version for colours)

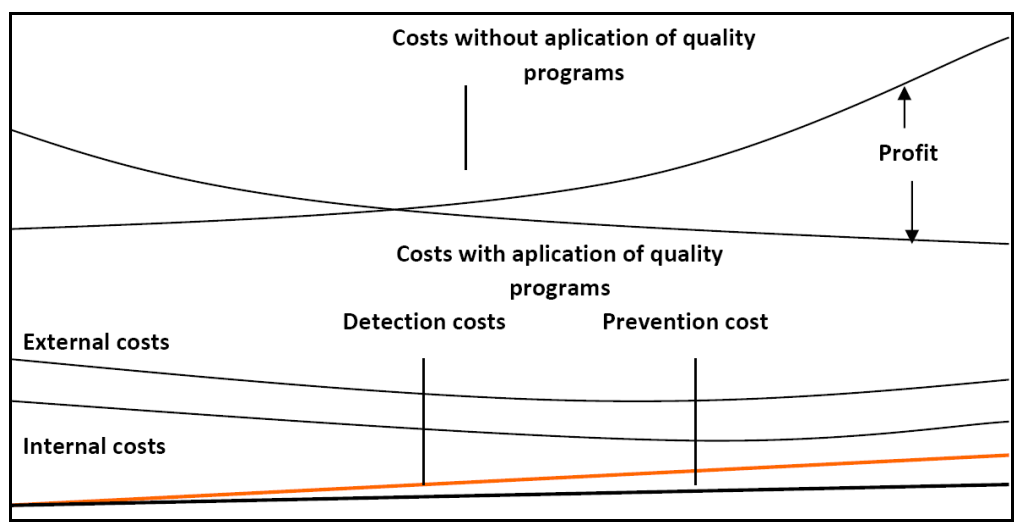

Source: Derek (2003, p.92)

Organisation that use programs to improve quality, contribute reduction of the internal and external costs (Figure 1) in a long term. Also, it can be concluded that the costs of prevention and detection over time indicate very small increase, while the internal and external costs reduce. It is obvious from the figure one that organisation that will use quality programs over time will influence the reduction of their cost and have other benefits.

For organisation there is no single solution to achieving business excellence (Rowland-Jones, 2013). First of all, organisation should raise employees' levels of consciousness/awareness about the importance of quality improvement issues on firms' competitiveness, fostering every collaborator's involvement in programs oriented toward quality improvement (Mendes, 2012). TQM cannot be successfully introduced or practiced, unless staff at all levels are informed and committed. Both the more successful companies, Companies A and B, ensured that every employee understood enterprise policy, vision, standards and procedures, and that these coincided with medium and long-term plans (Nizam and Tannock, 2005). 


\section{TQM techniques in sport organisations}

The use of TQM techniques is universal - they can be implemented in different types of organisations. In this paper we recommend implementation of TQM techniques in sport organisations. Some sport organisations use one or two TQM techniques, our approach is that sport organisations need to implement all five techniques in order to expect improvements in the overall organisation performance. The techniques that we recommend are: quality circles, benchmarking, continuous improvement (kaizen), empowerment and outsourcing, which are presented in the conceptual framework (Figure 2).

Figure 2 Conceptual framework

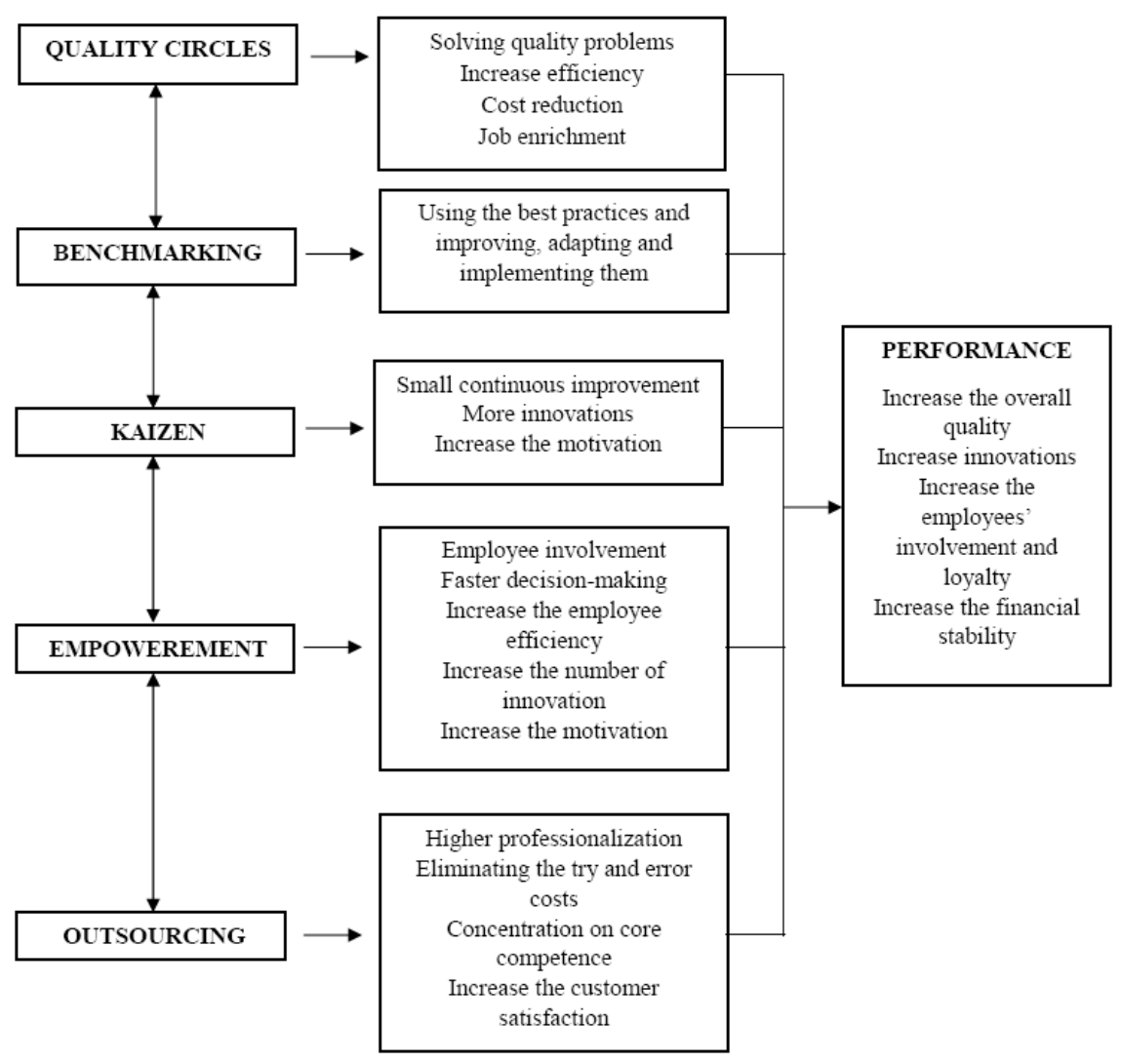

\subsection{Quality circles}

W.E Deming is the first author who noticed that the classic approach, where only managers should be involved in problem-solving, is wrong. He suggested new approach in problem solving, called 'quality circles' (Arnold, 1981). Quality circles are small group of employees mainly from the same field who meet regularly and voluntarily with the aim of identifying, solving and implementing the solution to the problems related 
with their work (Ira, 1979; Syla and Rexhepi, 2013). This group of employees (usually three-seven) is aiming all problems that are related with the improvement of quality in sport organisation. There are more than eight million employees, member of the quality circles, only as part of registered quality circles (Ira, 1979; Syla and Rexhepi, 2013). Research result proved that the cost-benefit from the implementation of quality circles in organisation is from $2: 1$ to $14: 1$. US organisations had an increase from $3 \%$ on productivity, compared to $9 \%$ increase in Japan organisations that used quality circles (Mohr and Mohr, 1983). Sport organisations in order to use the benefits of quality circles need to use participative management. Sport organisations that use autocratic management would not be able to use the benefit from quality circles. Ass Robert Cole from Michigan University states: "you cannot simply put quality circles in a hostile environment and expect a positive result" (as cited in Mohr and Mohr, 1983). The use of quality cycles include a basic assumption that most of the people are intelligent enough to do a work; people have brains, it is important to give them the opportunity to prove their mental abilities in a constructive way (Rexhepi, 2010).

\subsection{Benchmarking}

Benchmarking is a technique that management select and use the best practice from other organisation (Shuklev, 2015). Benchmarking uses external comparison in order to better valuate its own performance (Schermerhorn and Bachrach, 2015). Benchmarking can be defined as technique of TQM that constantly does comparison between departments in the organisation or the environment with its aim the use of best practices, improvement, adaptation and implementation of these practices (Rexhepi, 2010). Managers of sport organisations need to make distinction between benchmark which means measurement of the best performance and simple comparison, and benchmarking that further uses this result to make decision that will increase sport organisations' performance.

The success of the Japanese organisations is assumed that lays in benchmarking. Japanese organisations are recognised for their perfect ability to use best practices improve, adapt and then implement them in their own organisations. Benchmarking influences the sport organisations to be oriented externally. It makes the organisations to understand what are they doing poorer than the other organisations, and then learn from the best organisations (best in class) how to improve its performance (Leibfried and McNair, 1992). Sport organisations can learn not only from the other sport organisations, but also from other types of organisations. For example, finances are managed almost in the same way in every organisation and you can learn from the best practice, no matter in which sector operate the organisation.

There four type of benchmarking that can be used from a sport organisation in order to improve the overall quality (Shuklev, 2015):

1 Internal benchmarking - means learning from itself. It is an analysis of the current practice of working inside, in different departments and divisions inside the organisation. Best way to start using benchmarking is internally, where departments can learn from each other on what they are doing best.

2 Competitive benchmarking - is oriented toward learning positive and negative side of the competition (main competitors). 
3 Industrial benchmarking - is comparison with 'one by one' with the competition.

4 Best in class - is looking for new innovative approach in other industries, no matter what is their main activity. Sport organisations can learn from any type of organisation - if we want to have the best organisational structure, we can learn from an organisation that has the best structure, then we can search for an organisation that is best in class regarding the payment policies, then another one who has the best supply chain, etc.

Benchmarking has been advocated as a tool for improving management within the sport industry (Böhlke and Robinson, 2009), mainly for two reasons. The first was the sporting success achieved by the former German Democratic Republic (GDR) during the 1970s and 1980s, which showed that an organised approach towards the support of high performance sport could result in the systematic production of successful international athletes. The second, and perhaps more important event, was the success the Australian Institute of Sport (AIS) enjoyed in the build up to the 2000 Olympic Games. As the main elements of the AIS were based on the GDR system, this suggested that it was possible to achieve success by benchmarking elite sport systems against the infrastructure and processes to be found in other successful sporting nations (Böhlke and Robinson, 2009).

\subsection{Continuous improvement}

When we define quality in sport organisations, it is important to understand that quality is related with time and space. What we describe as quality today, we might not do the same after some time and also many people percept it differently. Quality is not absolute, as nothing else is - Albert Einstein confirmed this. Sport organisations need to continuously adapt quality to time and space requirements. Japanese organisations, including the sport organisation as well, use the approach even if it is good, make it better, while the American ones say that if it is good, leave it. Continuous improvement requires from sport organisations to have small and minor changes in their organisations. The success of the sport organisations depends on the development of these small and minor changes. This should be done on everyday bases. It is defined as continuously search of new ways on how to improve the actual performance (Daft and Marcic, 2013). It means implementation of many small improvements in all part of the sport organisations all the time (Daft and Marcic, 2013).

Continuous improvement should be the way of working and living inside the sport organisation, for every employee in the whole organisation. The role of everyone is equally important in the system - sport organisation. In order to make continuous improvement as part of the sport organisation, as an available tool for sport managers is the so called manager's walk. According to this technique, the manager every day goes to organisation's departments and makes a short conversation with their employees. They talk about the work that they are doing and what they could do differently in order to improve their performance, and what the management of the sport organisation can do and help them toward this. Here, the employees are treated as they are experts in their work (Bodek, 2015). This technique is also known as kaizen (in Japanese), where kai means change and zen, better. In Japan with the use of this technique yearly every employee delivers 24 new ideas (Bodek, 2015). 


\subsection{Empowerment}

The use of this technique requires substantive changes on the approach toward the employees in the sport organisation. Usually in sport organisation employees are not motivated to show their ideas or to point out a problem; in most of the cases they are unmotivated. Employees in this organisation are motivated to work according to their previously set standards. The first dilemma in using empowerment is what it makes different from delegation. Empowerment it is consisted from three elements (Mullins, 2013):

1 both of the parties are included

2 delegation is included

3 they have more effects - most of them are oriented toward employee engagement.

Empowerment generally is explained as giving more freedom to employees, more autonomy and self-control over their work and responsibility in decision making (Mullins, 2013). Empowerment is a process of enforcing the individual and group capacity to achieve its goal and transform this decision into desirable results (Christopher and Woolcock, 2005). For successful implementation of this technique it is necessary to analyse it from three dimensions:

a direction of the employees in the sport organisation

b ability of the employees in sport organisation

c the mutual trust among employees and especially employees and their managers.

The biggest benefit that sport organisation can expect is increased employees' engagement, more innovations, increased employees' efficiency, improved of the overall quality, etc. (Rexhepi, 2010).

In Table 3 we can notice the differences between organisations that use empowerment in their organisational culture and those who do not use it.

Table 3 Differences between organisations with hierarchal culture and empowerment culture

\begin{tabular}{lc}
\hline Hierarchal culture & Empowerment culture \\
\hline Planning & Vision \\
Ordering and control & Gathered for quality \\
Monitoring & Individual monitoring \\
Individual responsibility & Team responsibility \\
Pyramidal structure & Cross-functional structure \\
Current processes & Project \\
Managers & Trainer/team leaders \\
Employees & Members of team \\
Participative management & Individual team management \\
Work as you been told & Own your own job \\
Agreement & Good evaluation \\
\hline
\end{tabular}

Source: Adapted from Randolph (2000) 
Research result usually showed that employees tend to show better performance when an organisation use empowerment (Meyerson and Dewettinck, 2012). Employees tend to be more motivated when they are involved in sport organisation in setting their goal, proposing solution, etc.

\subsection{Outsourcing}

Another problem that sport organisations face is that they can excel in offering one service or in performing one activity, but fail in another service or activity. This is because sport organisations are enabled to concentrate in all activities in excellence; they usually put their effort in their core competence. Even though that sport organisations need to deliver excellence in quality for all activities. Outsourcing means executing of an organisational function by another organisation, which is specialist in their field (Shuklev, 2015). Outsourcing represents a positive exploitation of external differences in costs, skills, and employees' productivity in order to achieve competitive advantage (Gardner, 2003). Outsourcing is usually when managers hire others to do things that the organisation do not want to lose time and resources (Harriman, 2003). Outsourcing organisations are growing tremendously, where only for ITs were spent more than 23 billions \$ (Brower, 2000). Advantages of using outsourcing are summarised as follow (Vara and Jonathan, 2003):

- release of capital from the fixed assets, which can be used for improvement of the cash flow of the organisation, etc.

- the service is performed from a specialist

- it allows managers more time to dedicate to the core activities

- part of the risk is taken from the outsourcer.

But, the main advantage from using outsourcing is the reduction of risk from 'tries and errors'. Sport organisations need to pay huge attention to the agreement, which sometimes might have hidden costs that may ruin their competitive advantage as a result of using outsourcing (Jerome, 2001).

The use of TQM by sport organisations is not the ending goal. Its implementation is very important for the success of the quality program. Some research point out that lack of quality is the main reason why organisations are not showing positive result (Kumar et al., 2011). Even though TQM techniques showed great result in different organisation, still it is supposed that TQM benefits have not been explored fully (Choong, 2004).

\section{Conclusions}

One of the main points of this paper is to show the role of quality in sport organisations performance, and by that, the role that quality should have in management of these organisations. This paper tries to prove that sport organisations should pay much more attention to quality and try to implement it in every part and stage of their development, and make it as a crucial part of the management decision process. Researches show that implementation of the quality programs in organisations significantly improve their 
overall performance. Also, implementation of the TQM has shown great results in lowering the overall costs and that these costs' reduce comes mainly after three years (Rexhepi, 2010).

\section{References}

Arnold, K. (1981) The Far Side of Quality Circles, AMACOM, New York.

Beheshti, H.M. and Lollar, J.G. (2003) 'An empirical study of US SMEs using TQM', Total Quality Management and Business Excellence, Vol. 14, No. 8, pp.839-847.

Besterfield, H.D., Besterfield-Michina, C., Besterfield, H.G. and Besterfield, M.S. (2003) Total Quality Management, 3rd ed., Pearson Prentice Hall, Delhi.

Bodek, N. (2015) Continuous Improvement: A Three Legged Stool (TQM - LEAN Quick and Easy Kaizen) [online] http://www.saferpak.com/kaizen_art1.htm (accessed 3 October 2015).

Böhlke, N. and Robinson, L. (2009) 'Benchmarking of élite sport systems', Management Decision, Vol. 47, No. 1, pp.67-84.

Brower, J.M. (2000) An Economic Interpretation of Privatization and Outsourcing [online] http://static1.1.sqspcdn.com/static/f/702523/9458910/1290010966777/199901Brower.pdf?token=wgzJQy\%2BYqqqRbyRDXHMhlPb1r4Y\%3D (accessed 3 October 2015).

Choong, Y.L. (2004) 'Perception and development of total quality management in small manufacturers: an exploratory study in China', Journal of Small Business Management, Vol. 42, No. 1, pp.102-115.

Christopher, G. and Woolcock, M. (2005) Empowerment and Local Level Conflict Mediation in Indonesia: A Comparative Analysis of Concepts, The World Bank, USA.

Cohen, P. (2012) Deming's 14 Points [online] http://www.hci.com.au/hcisite2/articles/deming.htm (accessed 15 August 2012).

Crosby, P.B. (1979) Quality is Free, 1st ed., McGraw-Hill, New York.

Daft, L.R. and Marcic, D. (2013) Understanding Management, 8th ed., South-Western College Publication, Mason.

Dana, L-P. and Ramadani, V. (Eds.) (2015) Family Businesses in Transition Economies: Management, Succession and Internationalization, Springer, Cham.

Davis, M., Aquliano, J.N. and Chase, B.R. (1999) Fundamentals of Operations Management, 3rd Edition, Irwin/McGraw-Hill, New York.

Derek, L.W. (2003) Operation Management: A Supply Chain Approach, 2nd ed., Thomson, New York.

Gardner, J. (2003) Outsourcing in Drug Discovery, Find/Svp, New York.

Harriman, B.B. (2003) Brown Brother Harriman [online] https://www.bbh.com/en-us/investorservices (accessed 13 October 2010).

Hegazy, A.F. (2012) 'Obstacles to applying total quality management to sport clubs in Al-Jouf, Saudi Arabia', World Journal of Sport Sciences, Vol. 6, No. 1, pp.1-5.

Ira, B.G. (1979) 'Introduction to quality cribs: an approach participative problem-solving', Industrial Management Solicit, Vol. 21, No. 5, pp.21-26.

Jerome, B. (2001) 'The hidden costs of IT outsourcing', MIT Sloan Management Review [online] http://sloanreview.mit.edu/article/the-hidden-costs-of-it-outsourcing/ (accessed 3 October 2015).

Kalia, M. and Elmazi, I. (2012) 'The relationship between promoting the human factors in quality management systems and improving organizational performance of small and medium enterprises in Albania', International Journal of Management Cases, Vol. 14, No. 2, pp.42-50. 
Karastathis, D., Afthinos, Y., Gargalianos, D. and Theodorakis, D.N. (2014) 'The EFQM excellence model: an exploratory attempt for assessing the Hellenic National Sport Federations', International Journal of Sport Management Recreation and Tourism, Vol. 14, No. C, pp.38-67.

Kumar, R., Garg, D. and Garg, T.K. (2011) 'TQM success factors in North Indian manufacturing and service industries', The TQM Journal, Vol. 23, No. 1, pp.36-46.

Leibfried, J.H.K. and McNair, C.M. (1992) Benchmarking: A Tool for Continuous Improvement, Harper Business, New York.

Lobo, X.M. and Jones, J. (2003) Quality Initiatives and Business Growth in Australian Manufacturing SMEs: An Exploratory Investigation [online] http://www.flinders.edu.au/sabs/ business/research/papers/03-3.pdf (accessed 15 June 2015).

Mendes, L. (2012) Employees' involvement and quality improvement in manufacturing small and medium enterprise (SME): a comparative analysis', African Journal of Business Management, Vol. 6, No. 23, pp.6980-6996.

Meyerson, G. and Dewettinck, B. (2012) 'Effect of empowerment on employees performance', Advanced Research in Economic and Management Sciences, Vol. 2, No. 1, pp.40-46.

Mohr, W. and Mohr, H. (1983) Quality Circles: Changing Images of People at Work, AddisonWesley Publishing, Boston.

Mullins, L. (2013) Management and Organizational Behaviour, 10th ed., Pearson, Harlow.

Nizam, R.M. and Tannock, D.T.J. (2005) 'TQM best practices: experiences of Malaysian SMEs', Total Quality Management \& Business Excellence, Vol. 16, No. 4, pp.491-503.

Nová, J. (2013) 'Current concepts of the quality in sport and their utilization in the Czech Republic', Ekonomika a Management, Vol. 2013, No. 4, pp.1-9.

Park Dahlgaard, S.M. (1999) 'The evolution patterns of quality management: some reflections on quality movement', Total Quality Management, Vol. 10, Nos. 4/5, pp.473-480.

Prabhjot, K. and Kumar, S.S. (2014) 'Evaluating the relationship and influence of critical success factors of TQM on business performance: evidence from SMEs of manufacturing sector', IUP Journal of Operations Management, Vol. 13, No. 4, pp.17-30.

Randolph, W.A. (2000) 'Rethinking empowerment: why is it so hard to achieve?', Organizational Dynamics, Vol. 29, No. 2, pp.94-107.

Ratten, V. (2011a) 'A social perspective of sports-based entrepreneurship', International Journal of Entrepreneurship and Small Business, Vol. 12, No. 3, pp.314-326.

Ratten, V. (2011b) 'Sport-based entrepreneurship: towards a new theory of entrepreneurship and sport management', International Entrepreneurship and Management Journal, Vol. 7, No. 1, pp.57-69.

Ratten, V. (2015) 'Athletes as entrepreneurs: the role of social capital and leadership ability', International Journal of Entrepreneurship and Small Business, Vol. 25, No. 4, pp.442-455.

Rexhepi, G. (2010) Total Quality Management, in Albanian, Logos-A, Skopje.

Rowland-Jones, R. (2013) 'A perspective on United Arab Emirates small and medium-sized enterprises management utilising the European Foundation for Quality Management concepts of excellence', Total Quality Management and Business Excellence, Vol. 24, Nos. 1-2, pp.210-224.

Sarkar, B. (1991) 'Total quality management: problems and prospects in India', Total Quality Management, Vol. 2, No. 3, pp.239-248.

Schermerhorn, R.J. (1993) Management for Productivity, 4th ed., McGraw Hill, New York.

Schermerhorn, J.R. and Bachrach, G.D. (2015) Introduction to Management, 13th ed., John Willey $\&$ Sons. Inc, New York.

Shuklev, B. (2015) Principles of Management, in Macedonian, Faculty of Economics, Macedonia.

Smith Jr., V.C. (1999) 'Total quality management', Global Journal of Engineering Education, Vol. 3, No. 1, pp.61-64. 
Smith, A. and Stewart, B. (1999) Sports Management: A Guide to Professional Practice, Allen and Unwin Pty Ltd, Australia.

Syla, S. and Rexhepi, G. (2013) 'Quality circles: what do they mean and how to implement them?', International Journal of Academic Research in Business and Social Sciences, Vol. 13, No. 2, pp.243-251.

Vara, B. and Jonathan, H. (2003) 'Better out than in?', Estates Gazette, No. 348 [online] http://www.estatesgazette.com/ (accessed 3 October 2009).

Wang, C-H. (2015) 'A longitudinal study of innovation competence and quality management on firm performance', Innovation: Management, Policy and Practice, Vol. 16, No. 3, pp.392-403. 